\title{
Aktivitas Zona Hambat Ekstrak Daun Kemangi (Ocimum americanum) terhadap Candida albicans
}

\author{
Donna Mesina Rosadini Pasaribu ${ }^{1}$, Susana E. Sudrajat ${ }^{2}$, Herlina J. Buarlele ${ }^{3}$ \\ ${ }^{1}$ Staf Pengajar Bagian Mikrobiologi Fakultas Kedokteran Universitas Kristen Krida Wacana \\ ${ }^{2}$ Staf Pengajar Bagian Farmakologi Fakultas Kedokteran Universitas Kristen Krida Wacana \\ ${ }^{3}$ Mahasiswa Fakultas Kedokteran Universitas Kristen Krida Wacana \\ Alamat Korespondensi: donna.pasaribu@ukrida.ac.id
}

\begin{abstract}
Abstrak
Pengobatan penyakit yang disebabkan jamur Candida albicans umumnya menggunakan antijamur sintetik. Dampak penggunaan antijamur terus menerus, dapat mengakibatkan resistensi. Daun kemangi mempuyai senyawa yang dapat menghambat pertumbuhan jamur. Penelitian ini bertujuan untuk mengetahui adakah zona hambat pada ekstrak daun kemangi (Ocimum americanum) terhadap pertumbuhan Candida albicans dan untuk mengetahui berapa kadar ekstrak daun kemangi yang menghasilkan zona hambat pertumbuhan Candida albicans. Penelitian ini menggunakan metode difusi agar, dengan cara maserasi daun kemangi menggunakan etanol $96 \%$ yang direndam 2 hari, setelah didapatkan ekstrak lalu ekstrak dipipet ke dalam cawan petri yang sudah diisi Sabouraud Dextrose Agar dengan biakan Candida albicans. kontrol (+) menggunakan ketokonazol 0,02 gram dan kontrol (-) tween 80 sebagai pebanding zona daya hambat. Hasil penelitian menunjukkan bahwa konsentrasi ekstrak $5 \mu \mathrm{L}$ menghasilkan zona hambat 9,56 mm, sedangkan konsentrasi ekstrak $60 \mu \mathrm{L}$ sampai $80 \mu \mathrm{L}$ menghasilkan zona 29,65 mm sampai dengan $32,46 \mathrm{~mm}$, lebih luas dari zona hambat yang dihasilkan ketokonazol (kontrol +), yaitu $28,71 \mathrm{~mm}$. Kesimpulan penelitian ini membuktikan bahwa ekstrak daun kemangi memiliki aktivitas anti jamur terhadap Candida albicans, konsentrasi ekstrak daun kemangi pada volume $60 \mu \mathrm{L}$ sampai $80 \mu \mathrm{L}$ menunjukkan zona hambat lebih luas dari ketokonazol kontrol positif.
\end{abstract}

Kata kunci : Ekstrak daun kemangi, anti jamur, metode dufusi agar, Candida albicans

\section{Antifungal Activity of Basil Leaves Extract (Ocimum americanum) against Candida albicans}

\begin{abstract}
Treatment of diseases caused by Candida albicans generally uses synthetic antifungals. Continuous use of these antifungals can result in resistance. Basil leaves have compounds that can inhibit fungal growth. This study aims to determine antifungal activity of basil leaf extract (Ocimum americanum) againts Candida albicans. Extract was prepared by macerating basil leaves in 96\% ethanol for 2 days. Antifungal activity was determined by a diffusion method using Sabouraud Dextrose Agar. Ketoconazole 0.02 gram was used as a positive control, whereas tween 80 was used as a negative control. The results showed that the extract concentration of $5 \mu \mathrm{L}$ resulted in a $9.56 \mathrm{~mm}$ inhibition zone, while $60 \mu \mathrm{L}$ to $80 \mu \mathrm{L}$ produced zones of $29.65 \mathrm{~mm}$ to $32.46 \mathrm{~mm}$, wider than the inhibition zones produced by ketoconazole (+ control), $28.71 \mathrm{~mm}$. This study proves that basil leaf extract has antifungal activity against Candida albicans, thus can be further explored as a source of natural antifungal.
\end{abstract}

Keywords: Basil leaf extract, Antifungi, Agar diffusion method, Candida albicans. 


\section{Pendahuluan}

Kandidiasis merupakan infeksi yang disebabkan oleh jamur, Candida albicans. Kandidiasis terjadi jika mempunyai faktor predisposisi yaitu ketika flora normal tubuh pertumbuhannya terganggu sehingga menyebabkan flora oportunistik mikrooranisme di dalam tubuh dapat tumbuh secara berlebihan dan mengakibatkan penyakit. Salah satunya adalah kandidiasis kutis yaitu penyakit infeksi pada kulit yang disebabkan oleh Candida albicans. Manifestasi klinis yang muncul gatal yang sangat hebat sampai menimbulkan lesi kulit, terjadi peradangan, semakin meluas, membentuk makula atau papul, dan sering ditemukan lesi satelit (lesi yang lebih kecil yang kemudian menjadi lebih besar). Lesi terlokalisasi di daerah lipatan kulit, genital, bokong, di bawah payudara, atau di daerah kulit yang lain. ${ }^{1}$ Kemangi merupakan salah satu tanaman obat tradisional yang dimanfaatkan di Indonesia. Berdasarkan penelitian yang dilakukan kandungan kimia kemangi berupa minyak atsiri berperan sebagai antifungi, antioksidan, antimikroba, insektisida dan aktivitas terapeutik seperti anti-inflamasi, antipiretik, analgesik dan lain-lain. ${ }^{2} \quad$ Kandungan minyak atsiri di dalam daun kemangi yang diduga sebagai antifungi adalah methyl chavicol dan linalool. Minyak atsiri daun kemangi sebagai agen penanganan kandidiasis dapat ditentukan melalui mekanisme antifungi, dimana zat aktif minyak atsiri daun kemangi dapat merusak membran sel jamur sehingga molekul-molekul sel jamur lisis yang mengakibatkan kematian sel jamur. Molekul minyak atsiri juga dapat mengganggu kerja enzim-enzim yang terikat pada membran sel khamir, sehingga mengganggu pembentukan membaran sel dengan kata lain minyak atsiri dapat membunuh dan menghambat pertumbuhan jamur. ${ }^{3,4}$

Berdasarkan uraian di atas, untuk mengetahui apakah ekstrak daun kemangi mempuyai daya hambat dalam terhadap pertumbuhan Candida albicans dengan mengukur pembentukan zona hambat, pada media SDA (Sabouraud Dextrose Agar).
Adanya zona hambatan (zona hambat) yang muncul karena efek ekstrak daun kemangi, maka dapat diindikasikan bahwa daun kemangi diduga mempunyai senyawasenyawa antifungal.

\section{Kandungan Kimia Daun Kemangi}

Daun kemangi mengandung beberapa bahan kimia didalamnya yaitu saponin, flavonoid, tanin dan minyak atsiri. Minyak atsiri dapat menghambat sintesis asam nukleat, menghambat fungsi membran sitoplasma, dan menghambat metabolisme energi sel. ${ }^{5,6}$

Penelitian membuktikan bahwa minyak atsiri dari daun kemangi mempunyai efek antifungal pada area permukaan kulit, daun yang biasa digunakan sebagai makanan lalapan atau di jus mempunyai kandungan anti oksidan yang tinggi, penelitian lain juga membuktikan bahwa berkhasiat untuk melawan berbagai jenis infeksi, menyembuhkan sariawan, menghilangkan mual, mengobati flu, mengurangi demam, muntah, batuk, asam urat, peluruh haid, pembersih darah setelah bersalin, dan untuk memperbaiki fungsi lambung. ${ }^{7,8}$ Senyawa kimia yang membuat aroma kemangi adalah sitrat, memberi aroma yang khas sehingga daun kemangi banyak digunakan sebagai bahan tambahan untuk memasak, dan wangi minyak atsiri kemangi dipakai untuk bahan campuran obat dan kosmetika perawatan tubuh, misalnya sabun mandi, parfum, body lotion, permen pelega tenggorokan, minyak aromaterapi. ${ }^{8,9}$

\section{Candida albicans}

Candida albicans merupakan Divisi Eurycophyta, Kelas Deuteromycetes, Ordo Cryptococcaceae dan Famili Candidoidea dengan Genus Candida. ${ }^{10,11}$

Karakteristik morfologi Candida albicans merupakan jamur dismorfik karena kemampuannya untuk tumbuh dalam dua bentuk yang berbeda yaitu sebagai sel tunas yang akan berkembang menjadi blastospora dan menghasilkan kecambah yang akan membentuk hifa semu. Perbedaan bentuk ini tergantung 
pada faktor eksternal yang mempengaruhinya. Sel ragi (blastospora) berbentuk bulat, lonjong atau bulat lonjong dengan ukuran $2-5 \mu$ x 3-6 $\mu$ hingga $2-5,5 \mu \mathrm{x}$ 5-28 $\mu$. Candida albicans memperbanyak diri dengan membentuk tunas yang akan terus memanjang membentuk hifa semu. Hifa semu terbentuk dari blastospora berbentuk bulat atau lonjong di sekitar septum. Pada beberapa strain, blastospora berukuran besar, berbentuk bulat atau seperti botol, dalam jumlah sedikit. Sel ini dapat berkembang menjadi klamidospora yang berdinding tebal dan bergaris tengah sekitar 8-12 $\mu .{ }^{10,11}$ Morfologi koloni Candida albicans pada medium padat Sabouraud dekstrosa agar, umumnya berbentuk bulat dengan permukaan sedikit cembung, halus, licin dan kadang- kadang sedikit berlipat-lipat terutama pada koloni yang telah tua. Umur biakan mempengaruhi besar kecil koloni. Warna koloni putih kekuningan dan berbau asam seperti aroma tape. Dalam medium cair seperti glucose yeast, extract pepton, Candida albicans tumbuh di dasar tabung. ${ }^{12}$

Angka kejadian infeksi jamur, 70$80 \%$ disebabkan Candida albicans, dari kejadian tersebut $81 \%$ adalah kandidiasis kutis, dimana kejadian paling sering terjadi pada pasien immunokompromais, sedangkan 30\% infeksi disebabkan spesies Candida yang lain. Candida albicans sering ditemukan sebagai jamur saprofit dan berkoloni di membran mukosa pada hewan berdarah panas. Sekitar 50\% dari individu normal, mengalami kolonisasi di orofaring, selain itu Candida albicans merupakan organisme komensal pada mukosa vagina, $20-25 \%$ dari wanita sehat yang tidak memiliki gejala. Jamur ini jarang diisolasi dari kulit normal kecuali pada area intertriginosa yang kadang-kadang dapat ditemukan kolonisasi Candida. ${ }^{10,13}$

Infeksi Candida albicans diawali ketika mampu invasi dan menempel dalam jaringan kemudian berpenetrasi ke dalam sel epitel mukosa, host bila terdapat faktor predisposisi. Faktor predisposisi berperan dalam meningkatkan pertumbuhan Candida albicans serta memudahkan invasi jamur ke dalam jaringan tubuh host karena adanya perubahan dalam sistem pertahanan tubuh.
Di jaringan sel epitel mukosa, blastospora berkembang menjadi hifa semu dan tekanan dari hifa semu tersebut merusak jaringan, sehingga invasi ke dalam jaringan dapat terjadi. Enzim-enzim yang berperan sebagai faktor virulensi adalah enzim-enzim proteinase, lipase dan fosfolipase. ${ }^{14,15}$ Tidak terkontrolnya pertumbuhan Candida, bisa diakibatkan karena penggunaan kortikosteroid dalam jangka waktu yang lama, atau penggunaan obat-obatan yang menekan sistem imun serta penyakit yang menyerang sistem imun seperti Acquired Immunodeficiency Sindrome dan manifestasi kandidasis juga bisa karena gangguan keseimbangan mikroorganisme dalam mulut yang diakibatkan penggunaan antibiotik yang tidak terkontrol. ${ }^{15,16}$

\section{Metode Penelitian}

Penelitian ini adalah deskriptif laboratorium, dilakukan di Laboratorium Skripsi dan Laboratorium Riset FK UKRIDA pada bulan Agustus-Januari 2018. Subjek panelitian daun kemangi (Ocimum americanum) dan Isolat Candida albicans, Laboratorium riset FK UKRIDA.

Bahan penelitian yang digunakan adalah Saboroud Dextrose Agar (SDA), Saboroud Dextrose Broth (SDB), aquadest, mineral oil, twenn, ethanol, nitrogen, Polyethylen glycol (PEG) 4000 dan 400.

Alat Penelitian terdiri dari hot plate stirrer, Erlenmeyer $100 \mathrm{ml}$ dan $500 \mathrm{ml}$, batang pengaduk, kertas saring, evaporator, water bath, cawan, tabung reaksi, micropipette $20 \mu \mathrm{L}, 200 \mu \mathrm{L}, 1000 \mu \mathrm{L}$, pipet volume $10 \mathrm{~mL}$, autoklaf, inkubator, spreader, ose, lampu spiritus, gelas ukur dan cawan petri.

\section{Membuat Ekstrak Daun Kemangi}

Sebanyak $2 \mathrm{~kg}$ daun kemangi dicuci dengan air, dipotong kecil-kecil dan diangin-anginkan di bawah AC hingga kering lalu ditimbang 2 hari sekali hingga berat konstan, daun kemangi dihaluskan menggunakan blender hingga menjadi serbuk, lalu diekstraksi. ${ }^{15-17}$ 


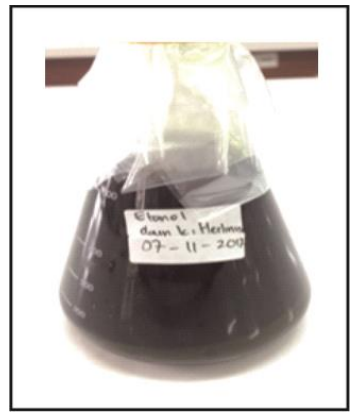

Gambar 1. Serbuk Daun Kemangi 50 gr dilarutkan dalam etanol sebanyak $500 \mathrm{ml}$

Ekstraksi dilakukan dengan menggunakan metode maserasi atau perendaman, serbuk daun kemangi ditimbang sebanyak 50 gr dalam tabung Erlenmeyer dan diisi etanol 96\% hingga mencapai volume $500 \mathrm{~mL}$. Perendaman dilakukan selama 2x24 jam. Hasil rendaman daun kemangi dalam etanol $96 \%$ tersebut disaring menggunakan kertas saring. Filtrat yang didapat kemudian dipekatkan dengan cara menguapkan etanol $96 \%$ pada evaporator. Filtrat dituangkan dalam labu bulat lalu direndam dalam waterbath pada suhu $60^{\circ} \mathrm{C}$ dan dihubungkan menggunakan rotary evaporator pada tekanan $3 \mathrm{~atm}$ hingga terbentuklah ekstrak kental. Untuk memastikan tidak ada lagi etanol yang tertinggal, ekstrak dinitrogen selama 1 jam sambil dilakukan penimbangan hingga didapatkan ekstrak daun kemangi dengan berat yang stabil. ${ }^{16-17}$

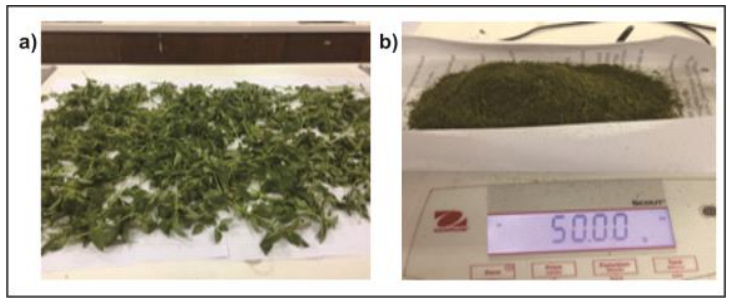

Gambar 2. a) Daun Kemangi Sebelum

Dikeringkan, b) Serbuk Daun Kemangi Telah Diblender

\section{Proses Ekstraksi}

Metode yang digunakan adalah metode maserasi, merupakan proses perendaman sampel menggunakan pelarut etanol 96\% karena etanol merupakan pelarut yang umum digunakan untuk mencari senyawa polar maupun non polar.
Pelarut yang digunakan akan menembus dinding sel dan akan masuk ke rongga sel yang mengandung senyawa aktif. Senyawa aktif larut karena terdapat perbedaan konsentrasi antara larutan senyawa aktif di dalam dan luar sel, maka cairan hipertonis yang akan masuk ke cairan yang hipotonis sehinnga terjadi keseimbangan. Metode ini dipilih untuk mencegah adannya kerusakan komponen senyawa oleh suhu yang tinggi

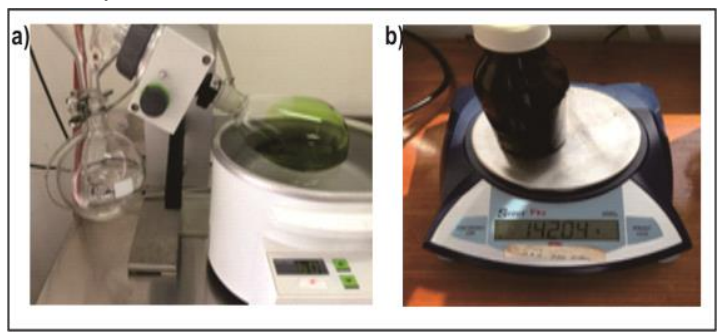

Gambar 3. a) Evaporasi Ekstrak Daun Kemangi Menggunakan Rotary Evaporator, b) Ekstrak Daun Kemangi yang Telah Dipekatkan

\section{Membuat Media Tumbuh Candida albicans}

Bubuk SDA ditimbang sebanyak 13 gr yang dimasukan ke dalam tabung Erlenmeyer, lalu kemudian dilarutkan ke dalam aquadest $200 \mathrm{~mL}$, dipanaskan dengan menggunakan hot plate stirre sambil diaduk menggunakan stirre hingga semua homogen dan larut (didapatkan larutan yang jernih). Erlenmeyer yang berisikan SDA ditutup lalu disterilisasi didalam alat autoklaf pada suhu $121{ }^{\circ} \mathrm{C}$ selama 20 menit. Setelah selama 20 menit tuang larutan SDA yang ke dalam 10 cawan petri. Diamkan sehingga SDA membeku, siap untuk digunakan. ${ }^{16,17}$

Bubuk SDB ditimbang sebanyak 3 gr yang dimasukan ke dalam tabung erlemeyer, lalu dilarutkan dengan aquadest $100 \mathrm{~mL}$. Larutan diaduk menggunakan batang pengaduk hingga didapatkan larutan yang jernih. Kemudian SDB dibagi ke dalam beberapa tabung atau Erlemeyer sesuai kebutuhan. Tabung atau Erlenmeyer yang berisi SDB ditutup disterilisasi di dalam autoklaf pada suhu $12^{\circ} \mathrm{C}$ selama kirakira 20 menit. SDB dalam tabung atau Erlenmeyer, siap unmtuk digunakan. 


\section{Inokulasi Candida albicans}

Stock isolat Candida albicans diinokulasi kedalam tabung Erlenmeyer yang berisi media SDB $30 \mathrm{~mL}$, ditutup dengan kapas steril dan diinkubasi selama 24 jam di dalam incubator dengan suhu $37^{0} \mathrm{C} \cdot{ }^{15-17}$

\section{Pembuatan Standar Turbiditas Inokulum Candida albicans}

Metode pembuatan kurva tumbuh ini dinamakan metode turbiditimetri, biakan jamur yang sudah diinokulasi ke dalam SDB diambil sedikit demi sedikit menggunakan micropipette sebanyak 3.5 $\mu \mathrm{L}$ dan dimasukan ke dalam $7 \mathrm{ml}$ SDB yang telah steril. Setelah itu dilihat kekeruhannya menggunakan spektrofotometer sesuai dengan standar turbiditas 0.5 McFarland, $530 \mathrm{~nm}$ untuk mendapatkan jumlah inoculum yang dianggap sesuai dengan $5 \times 10^{6} \mathrm{CFU} / \mathrm{ml}^{15}$

\section{Uji Aktivitas Daya Hambat Ekstrak Kemangi terhadap Candida albicans}

Penggujian aktivitas ekstrak etanol daun kemangi terhadap pertumbuhan Candida albicans dilakukan dengan menggunakan metode difusi sumur (well diffusion method) yang telah dimodifikasi. $^{17,18}$ Sebanyak $100 \quad \mu \mathrm{L}$ suspensi yang sudah sesuai dengan standar McFarland dipipet lalu disebarkan pada permukaan media SDA menggunakan alat Spreader. Selanjutnnya dibuat sumur atau lubang dengan menggunakan perforator dengan masing-masing diameter yang telah disesuaikan dengan masing jumlah ekstrak. Ekstrak yang diiuji sebanyak $5 \mu \mathrm{L}, 10 \mu \mathrm{L}$, $15 \mu \mathrm{L}, 20 \mu \mathrm{L}, 30 \mu \mathrm{L}, 40 \mu \mathrm{L}, 50 \mu \mathrm{L}, 60 \mu \mathrm{L}$, $70 \mu \mathrm{L}, 80 \mu \mathrm{L}$, lalu dipipet ke dalam sumur kecil yang sudah di bentuk di SDA . Kemudian di sumur yang satunnya lagi diberikan larutan ketokonazol dalam dengan konsentrasi $2 \%$ digunakan sebagai control positif, untuk kontrol negative digunakan tween sebanyak $10 \mathrm{ml}$. Inkubasi pada suhu $37^{\circ} \mathrm{C}$ selama 24 jam. Hasil pengujian diperiksa berdasarkan terjadinnya zona hambat disekitar koloni yang merupakan zona hambat terhadap pertumbuhan koloni dari setiap konsentrasi ekstrak. Uji ini dilakukan triplet atau 3 kali pengulangan.

\section{Parameter yang Diperiksa}

Parameter yang diperiksa dalam penelitian ini adalah zona hambat ekstrak daun kemangi terhadap pertumbuhan Candida albicans. Yang menjadi Variabel terikat dalam penelitian ini adalah zona hambat yang terbentuk pada uji hambat antijamur Candida albicans dan variabel bebasnya adalah kadar dari ekstrak kemangi

\section{Hasil dan Pembahasan}

Proses pengeringan daun kemangi yang akan diekstrak dilakukan secara terusmenerus hingga didapatkan berat daun kemangi yang konstan. Setelah berat konstan, daun tersebut kemudian di blender hingga menjadi serbuk. Proses ini dilakukan untuk meningkatkan luas permukaan kontak antara senyawa yang terdapat dalam daun kemangi dengan pelarut yang akan digunakan. Serbuk daun kemangi kemudian disimpan di dalam kulkas untuk menghindari terjadinnya kerusakan. Jadi susut pengeringan dari daun kemangi adalah bobot daun kemangi awal dikurang bobot daun kemangi tetap

Tabel 1. Uji Susut Pengeringan

\begin{tabular}{cc}
\multicolumn{2}{c}{ Daun Kemangi } \\
\hline Tanggal & $\begin{array}{c}\text { Berat } \\
(\mathbf{g})\end{array}$ \\
\hline $11 / 11-17$ & 2000 \\
$12 / 11-17$ & 1150 \\
$13 / 11-17$ & 910 \\
$14 / 11-17$ & 800 \\
$16 / 11-17$ & 660 \\
$19 / 11-17$ & 580 \\
$20 / 11-17$ & 540 \\
$24 / 11-17$ & 540 \\
\hline$=2000 \mathrm{~g}-540$ \\
$=1460 \mathrm{~g}$ \\
$\frac{1460}{2000} \times 100 \%=73 \%$
\end{tabular}


Jadi, susut pengeringan daun kemangi tersebut adalah $73 \%$, artinya kandungan air yang yang terbawa sewaktu mencuci daun kemangi sudah hilang.

\section{Penentuan Berat Kering Sampel}

Untuk menentukan berat kering dari masing-masing sampel dilakukan dengan cara evaporasi. Setelah maserasi dilakukan evaporasi menggunakan rotary evaporator dengan suhu $60^{\circ} \mathrm{C}$, pada tekanan $300 \mathrm{~atm}$. Metode evaporasi ini adalah metode untuk mendapatkan ekstrak yang pekat dari sampel dengan cara menguapkan pelarut organik yang dapat digunakan dalam pembuatan sampel tersebut. Ekstrak yang sudah pekat dimasukan dalam botol lalu dialiri gas nitrogen untuk mengeluarkan pelarut yang tidak dapat diuapkan lagi dengan evaporator. Proses pengaliran gas nitrogen ini dilakukan hingga berat dari ekstrak tersebut stabil.

Rendemen adalah suatu perbandingan antara hasil ekstrak daun kemangi yang diperoleh dengan simplisia awal. Rumus untuk menhitung rendaman adalah sebagai berikut:

$$
\begin{gathered}
\text { Rendemen }=\frac{\text { Berat ekstrak kental }}{\text { Volume }} \times 100 \% \\
=\frac{7,71}{8} \times 100 \% \\
=0,964 \%
\end{gathered}
$$

Rendemen yang dihasilkan dalam penelitian ini adalah $0,964 \%$ artinya dalam 500 gram daun kemangi kering mengandung $\quad 0,964 \%$ minyak atsiri. Rendemen memperkirakan perbandingan perolehan destilat yang didapat, sehingga kita bisa estimasi kebutuhan sampelnya atau untuk menentukan berapa dosis destilat dengan melihat nilai rendemen.

Berat kering sampel ekstrak :

$$
\frac{964 g r}{1000 \mu L}=\frac{964 g r}{1 m L}=0,964 \frac{g r}{m L}
$$

yang berarti dalam $1 \mathrm{~mL}$ ekstrak daun kemangi setara dengan 0,964 gram.

Konsentrasi Hambat Minimal Ekstrak Daun Kemangi terhadap Candida albicans. Penelitian daya hambat dapat dilakukan dengan cara, menggunakan ekstrak yang sudah didapatkan dengan pengulangan 3 kali (triplet). Pengumpulan data dilakukan dengan mengukur adanya diameter zona hambat yaitu zona hambat di sekitaran semuran yang tidak ditumbuhi jamur Candida albicans. Data yang diperoleh dikelompokan menjadi 3 kategori yaitu:

- Diameter 11-15 mm dalam kategori resisten

- Diameter 16-20 mm dalam kategori intermediet

- Diameter $>20 \mathrm{~mm}$ termasuk sensitive $^{15-17}$

Hasil penelitian ekstrak daun kemangi terhadap jamur Candida albicans menunjukkan bahwa konsentrasi ekstrak daun kemangi (Ocimum americanum) yang diujikan dalam inkubasi $2 \times 24$ jam memiliki aktivitas daya hambat terhadap pertumbuhan Candida albicans. Hal ini dapat dibuktikan dengan terbentuknnya zona hambat di sekitar lubang sumuran dengan tiga kali pengulangan. 


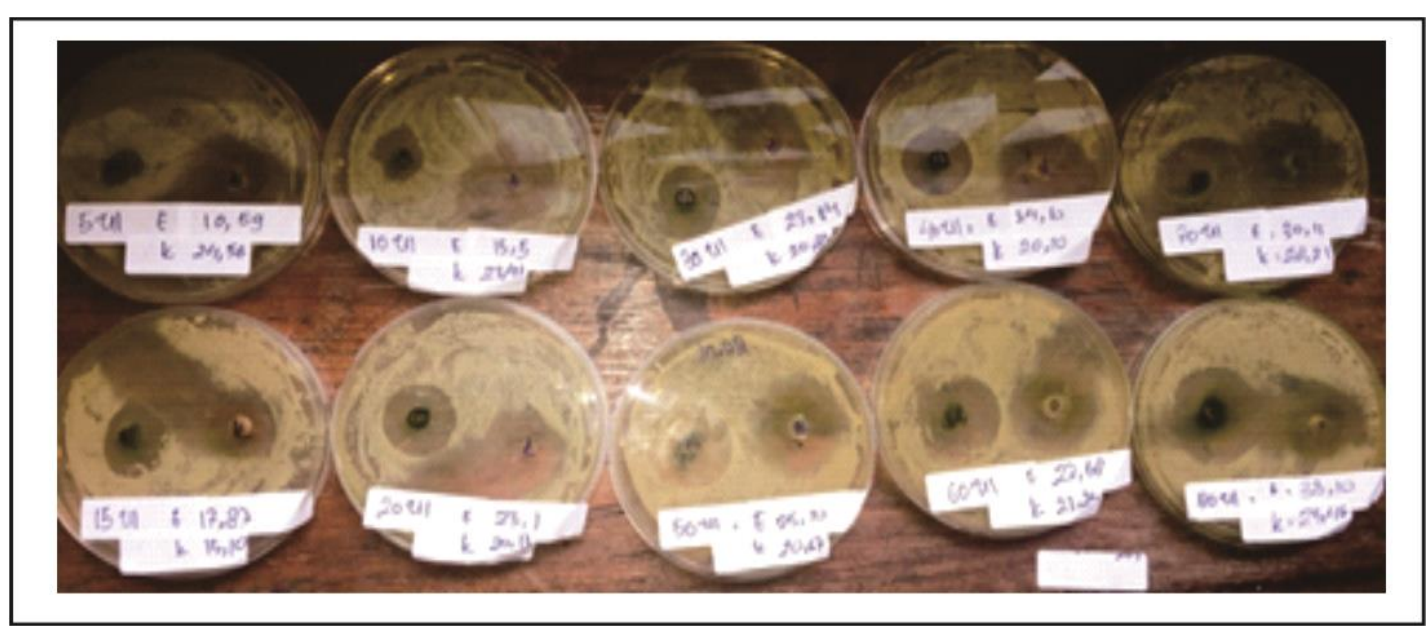

Gambar 4. Zona Hambat ekstrak Daun Kemangi terhadap Candida albicans dengan konsentrasi $5 \mu \mathrm{L}, 10 \mu \mathrm{L}, 15 \mu \mathrm{L}, 20 \mu \mathrm{L}, 30 \mu \mathrm{L}, 40 \mu \mathrm{L}, 50 \mu \mathrm{L}, 60 \mu \mathrm{L}, 70 \mu \mathrm{L}, 80 \mu \mathrm{L}$, Pengulangan Kedua

Tabel 2. Hasil Zona Hambat Ekstrak Daun Kemangi terhadap Candida albicans

\begin{tabular}{cccccc}
\hline $\begin{array}{c}\text { Konsentrasi } \\
(\mu \mathrm{L})^{*}\end{array}$ & \multicolumn{3}{c}{ Ulangan $(\mathrm{mm})$} & $\begin{array}{c}\text { Rata-rata } \\
\text { kontrol }(+)\end{array}$ & $\begin{array}{c}\text { Rata-rata } \\
(\mathrm{mm})^{* *}\end{array}$ \\
\hline 5 & 10,59 & 7,61 & 10,48 & 20,67 & $9,56 \pm 1,689645$ \\
10 & 15,50 & 13,10 & 13,22 & 23,24 & $13,94 \pm 1,352331$ \\
15 & 17,87 & 15,50 & 15,17 & 28,71 & $18,06 \pm 2,99468$ \\
20 & 23,10 & 17,87 & 23,18 & 24,21 & $23,12 \pm 0,04618$ \\
30 & 23,84 & 23,10 & 24,50 & 25,56 & $24,35 \pm 0,46198$ \\
40 & 24,10 & 27,88 & 25,17 & 26,67 & $25,71 \pm 1,94839$ \\
50 & 25,10 & 28,25 & 28,78 & 27,43 & $27,37 \pm 1,98938$ \\
60 & 27,68 & 30,89 & 30,10 & 26,55 & $29,65 \pm 2,86713$ \\
70 & 30,11 & 33,89 & 33,40 & 22,31 & $32,46 \pm 2,05558$ \\
80 & 33,00 & 36,67 & 35,78 & & \\
\hline
\end{tabular}

Ket * : Dengan satuan berat keringnya $0,964 \frac{\mathrm{gr}}{\mathrm{mL}}$

**: Rata-rata yang didapat hanya dari pengulangan 1,2, dan 3

Gambar 5. menunjukan bahwa semakin tinggi konsentrasi ekstrak daun kemangi, maka semakin besar zona hambat terhadap jamur Candida albicans. Hal ini karena semakin tingginya konsentrasi ekstrak daun kemangi berarti semakin banyak kandungan zat atau senyawa aktif yang terkandung didalamnya. Besarnya diameter zona hambat juga tergantung pada daya serap zat antijamur ke dalam lempeng agar dan kepekaan jamur terhadap zat antijamur tersebut. ${ }^{17-19}$ Berdasarkan hasil penelitian dan analisis statistik dengan menggunakan uji regresi linier didapatkan persamaan regresi diameter zona hambat $(\mathrm{Y}): \mathrm{Y}=17,236+2,3691$ konsentrasi $(\mathrm{X})$, dari persamaan regresi menunjukkan koefisien konsentrasi bernilai positif yang berarti ada pengaruh positif (searah) antara tingginya konsentrasi dan adannya zona hambat. Besaran koefisiennya berarti setiap adannya kenaikan konsentrasi sebesar $1 \mu \mathrm{L}$ $\left(0,964 \times 10^{-6} \mathrm{gr} / \mathrm{mL}\right)$ maka zona hambat akan membesar sebanyak 2,3691 $\mathrm{mm}$. Konstanta yang sebesar 1,7236 seacara matematis jika variabel bebas nilainnya 0 maka variable terikat nilainnya sebesar konstanta tersebut. Tetapi jika tidak konsentrasi ekstrak yang jumlahnnya 0 (berarti tidak masuk dalam analisis). 


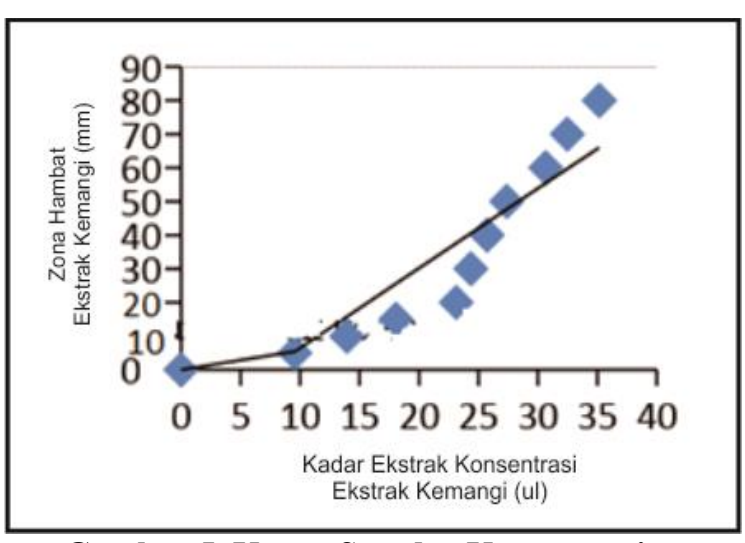

Gambar 5. Kurva Standar Konsentrasi Ekstrak Kemangi

Dengan menggunakan anova tentang uji daya hambat ekstrak daun kemangi terhadap pertumbuhan Candida albicans diperoleh data yang menunjukkan Dengan menggunakan Anova tentang uji daya hambat ekstrak daun kemangi terhadap pertumbuhan jamur Candida albicans diperoleh data yang menunjukan $\mathrm{F}$ tabel (Lampiran 1) sebesar 0,052 yang artinya $F$ hitung $>\mathrm{F}$ tabel. Hal ini menunjukan bahwa $\mathrm{H}_{0}$ ditolak sehingga $\mathrm{H}_{1}$ diterima, jadi ada pengaruh konsentrasi terhadap besarnya penghambatan jamur Candida albicans. Kemudian pada sig. F didapatkan bahwa sig. $F<0,05$ yang menunjukan bahwa pengaruh konsentrasi signifikan. Hasil analisis statistik dengan Anova dapat dilihat di Tabel 3.

Tabel 3. Analisis Anova

\begin{tabular}{cccccc}
\hline ANOVA & $d f$ & $S S$ & $M S$ & $F$ & Significance $F$ \\
\hline Regression & 10 & 543.681 & 54.3681 & 76.32007 & 0 \\
Residual & 8 & 56.98957 & 7.123696 & & \\
Total & 18 & 600.6706 & & & \\
\hline
\end{tabular}

Kemampuan antijamur oleh ekstrak disebabkan karena adannya komponen aktif yang terkandung didalamnya. Daun kemangi mengandung alkaloid dan minyak atsiri methyl chavicol dan linolol. Dalam ekstrak etanol, daun kemangi mengandung fraksi minyak atsiri yang berwarna coklat kehitaman yang apabila dioleskan di kulit memberikan rasa panas/hangat. Berdasarkan data tersebut diduga bahwa zat yang berkhasiat sebagai antijamur dari ektrak daun kemangi adalah minyak atsiri. Senyawa polar yang tertarik dalam ekstrak etanol seperti saponin, flavonoid dan minyak atsiri mempunyai aktivitas pada sel jamur dengan membentuk senyawa kompleks dengan sterol dari dinding sel, dan selanjutnya mempengaruhi permeabilitas membrane sel, sintesis asam nukleat, fosforilasi oksidatif dan transport elektron yang mengakibatkan gangguan metabolisme dan penghambatan pertumbuhan selnya. ${ }^{15,16,20}$

Dari penelitian tersebut ternyata semua ekstrak uji mempunyai efek hambat secara in vitro dengan metode difusi, dan dengan analisa fitokimia semua bahan alami tersebut mengandung komponen kimia seperti saponin, flavonoid dan minyak atsiri. Analisa ini dilakukan terbatas hanya dengan mereaksikan zat warna, sehingga tidak meliputi analisa komponen kimia yang menggunakan teknik gas chromatography dan mass spectrometry.

\section{Simpulan}

Hasil Penelitian ini menyimpulkan bahwa ekstrak daun kemangi memiliki aktivitas antijamur terhadap Candida albicans, dimana konsentrasi minimum ekstrak daun kemangi yang membentuk zona hambat terhadap pertumbuhan Candida albicans adalah $5 \mu \mathrm{L}$ dengan ukuran zona 9,56 mm. Konsentrasi ekstrak daun kemangi $60 \mu \mathrm{L}$ sampai $80 \mu \mathrm{L}$ menghasilkan zona hambat lebih luas dari ketokonazol (kontrol + ), dengan ukuran 29,65 mm sampai dengan 32,46 mm, sedangkan zona hambat ketokonazol terhadap pertumbuhan Candida albicans, menghasilkan zona $28,71 \mathrm{~mm}$. 


\section{Saran}

Kepada peneliti selanjutnya diharapkan dapat melakukan penelitian mengenai kandungan zat aktif dari daun kemangi yang memiliki aktifitas antifungi yang lebih spesifik dan mekanisme penghambatannya. Perlu dilakukan uji daya lain dari ekstrak daun kemangi yaitu antibakteri, antivirus dan antitumor untuk mengetahui aktifitas lainnya dari ekstrak daun kemangi yang lebih poten.

\section{Daftar Pustaka}

1. Angelina, M., Turnip, M., dan Khotimah, S. Uji aktivitas antifungi ekstrak etanol daun kemangi (Ocimum americanum) terhadap pertumbuhan bakteri Escherichia coli dan Candida albicans. Journal Protobiont. 4(1): p.184-9.

2. Ilyas M. Daya hambat ekstra Daun kemangi terhadap pertumbuhan Candida albicans. Dentofacial; 2014;; 7(1):7-12.

3. Harlen Kaur Sandhar, dkk. A review of phytochemistry and pharmacology of flavonoids. Journal of International Pharmaceutica Sciencia, 2015; 1: 2541

4. Alfiah, R, Khotimah, S., dan Turnip, M.. Efektivitas ekstrak metanol daun sembung rambat (Mikania micrantha Kunth) terhadap pertumbuhan jamur Candida albicans. Journal Protobiont. 4(1):52-7.

5. Lutfiyah, I. 2015. Pengaruh ekstrak daun kemangi terhadap pertumbuhan Candida albicans serta pemanfaatannya sebagai bahan ajar dalam pembelajaran biologi siswa SMA. Naskah Publikasi. Fakultas Pendidikan Matematika dan Ilmu Pengetahuan Alam, Universitas PGRI Semarang.

6. Ardo., S. Aktivitas antifungi flavonoid Ocimum americanum terhadap jamur Candida albicans (in vitro). Muhammadiyah Journal of Nurshing. 2016; 5(1):32-8.

7. Yuhana, S. A., Kusdarwati, R., \& Meles, D. K. Daya antibakteri ekstrak daun kemangi (Ocimum americanum.) terhadap Candida albicans secara in vitro. Jurnal Ilmiah Perikanan dan Kelautan. 2016; 4(3):122-3.

8. Kan,Y., Uçan, U.S., Kartal, M., Altun, M.L., Aslan, S., Sayar, E., dan Ceyhan, T. Analysis and antifungi activity of cultivated Satureja cuneifolia ten essential oil. Turkey Journal Chemitry 2015; 3(2): 253-9.

9. Candrasari, A., Romas, M.A., Hasbi, M., dan Astuti, O.R. Uji daya antimikroba ekstrak etanol daun kemangi terhadap pertumbuhan Staphylococcus Aureus atcc 6538, Eschericia Coli atcc 11229 dan Candida albicans atcc 10231 secara in vitro. Jurnal Biomedika Fakultas Kedokteran Universitas Muhammadiyah Surakarta. 2016; 4(1): 9-16.

10. Juliantina, F. R., dan Nurmasitoh, T. Manfaat Ocimum americanum sebagai agen antifungi terhadap jamur Candida albicans. Jurnal Kedokteran dan Kesehatan Indonesia. 2016; 7(1):121-6.

11. Brooks, G. F., Carroll, K. C., Butel, J. S., Morse, S. A., dan Mietzner, T. A. 2015. Jawetz, and Adelberg's Medical Microbiology. 24th Ed. New York: Mc Graw hill Comp p.218.

12. Umar, A.N.L. Perbandingan ekstrak daun kemangi (Ocimum basilicum L.) dengan $2 \%$ dalam menghambat pertumbuhan Candida sp. pada kandidiasis vulvovaginalis. Jurnal Protobiont. 2015; 3(2): 274-9.

13. Sabrina, T. I., Sudarno, dan Suprapto, $\mathrm{H}$. Uji aktivitas antifungi perasan daun kemangi (Ocimum americaum.) terhadap Candida albicans secara in vitro. Jurnal Ilmiah Perikanan dan Kelautan. 2015; 6(2):176.

14. Pelczar, M. J. dan Chan, E. C. S. 2014. Dasar-dasar mikrobiologi 2. Jakarta: UI Press.

15. Atikah, N. 2017. Uji aktivitas antimikroba ekstrak herba kemangi (Ocimum americanum L.) terhadap Staphylococcus aureus dan Candida ablicans. Jakarta: Skripsi UIN Syarif Hidayatullah.

16. Mahmoud, H. Nabil, H., Yousif, O. Effect of basil (Ocimum americanum.) 
leaves powder and ethanolic-extracton the 3rd larval instar of Anophelesarabiensis (Patton, 2016) (Culicidae:Diptera). International Journal of Mosquito Research. 2017; 4(2):52-6.

17. Erviana, L., Abdul, M., Ahmad, N. Uji aktivitas antiradikal bebas ekstrak etanol daun kemangi (Ocimum basilicum L.) dengan menggunakan metode dpph. Jurnal Fitofarmaka Indonesia.2016; 3(2):164-8

18. Lin, L., Wen, C., Chun, C. Antifungi natural products and herbal medicines.
Journal of Traditional and Complementary Medicine. 2015; 4(1):24-35.

19. Ozcan, M., Jean, C. Essential oil composition of Ocimum americanum. and Ocimum minimum L. in Turkey. Czezh Journal of Food Sci. 2015; 20(6):223-8

20. El-Soud, N., Mohamed, D., Lamia, A., Mona, K. Chemical composition and antifungal activity of Ocimum americanum essential oil. Journal of Medical Sciences. 2015; 3(3): 374-9. 